\title{
Retraction Note: Agricultural climate change based on remote sensing image and emergency material supply management of agriculture, rural areas and farmers
}

Di Xu ${ }^{1}$

Published online: 6 December 2021

(c) Saudi Society for Geosciences 2021

Retraction Note: Arabian Journal of Geosciences (2021)

\section{4: 894}

https://doi.org/10.1007/s12517-021-07221-0

The Editor-in-Chief and the Publisher have retracted this article because the content of this article is nonsensical. The peer review process was not carried out in accordance with the Publisher's peer review policy. The author has not responded to correspondence regarding this retraction.

The original article can be found online at https://doi.org/10.1007/ s12517-021-07221-0

Di Xu

Di_Xu@126.com

1 School of Marxism, Jiangnan University, Wuxi Jiangsu 214122, China 